\title{
Interleukin-6 regulates anti-arthritic effect of methotrexate via reduction of SLC19A1 expression in a mouse arthritis model
}

\author{
Misato Hashizume ${ }^{1 *}$, Hiroto Yoshida ${ }^{1}$, Keisuke Tanaka ${ }^{1}$, Miho Suzuki ${ }^{1}$, Isao Matsumoto ${ }^{2}$, Takayuki Sumida ${ }^{2}$ and \\ Masahiko Mihara ${ }^{1}$
}

\begin{abstract}
Introduction: Methotrexate (MTX) enters cells via the reduced folate carrier SLC19A1, suggesting that SLC19A1 is associated with the efficacy of MTX. We here examined the relationship between the efficacy of MTX and the expression of SLC19A1 in glucose 6-phosphate isomerase (GPI)-induced arthritis. We found that interleukin-6 (IL-6) regulated the expression of SLC19A1, so we studied the effect of a combination of MTX and anti-mouse IL-6 receptor antibody (MR16-1).
\end{abstract}

Methods: GPI-induced arthritis was induced by intradermal immunization with recombinant GPI. MTX was given from the first day of immunization. Mice were injected once with MR16-1 10 days after immunization. The levels of SLC19A1 mRNA in whole hind limbs and immune cells were measured. Synovial cells from arthritic mice were cultured with cytokines, and cell proliferation and gene expressions were measured.

Results: MTX inhibited the development of GPI-induced arthritis; however, the efficacy of MTX gradually diminished. SLC19A1 expression in immunized mice with arthritis was lower than in intact mice; moreover, SLC19A1 expression in arthritic mice was further decreased when they were treated with MTX. IL-6 was highly expressed in whole hind limbs of arthritic mice. In an in vitro study using synovial cells from arthritic mice, IL-6 + soluble IL-6 receptor (sIL-6R) weakened the anti-proliferative effect of MTX and reduced SLC19A1 expression. Finally, although MR16-1 did not improve arthritis at all when administered on day 10, MTX in combination with MR16-1 more potently reduced the development of arthritis than did MTX alone. When used in combination with MTX, MR16-1 apparently reversed the decrease in SLC19A1 induced by MTX alone.

Conclusions: In the present study, we demonstrated for the first time that IL-6 reduced the efficacy of MTX by decreasing the expression of SLC19A1, which is important for MTX uptake into cells.

\section{Introduction}

Methotrexate (MTX) is an anchor drug for the treatment of rheumatoid arthritis (RA) because of its efficacy, acceptable safety, and cost. MTX is used in monotherapy or in combination with either biological agents or other small molecule anti-rheumatic drugs [1-3]. Regarding its antirheumatic mechanisms, it has been reported that MTX promotes adenosine release, inhibits pro-inflammatory cytokine production, suppresses lymphocyte proliferation,

\footnotetext{
* Correspondence: hashizumemst@chugai-pharm.co.jp

1 Product Research Department, Fuji-Gotemba Research Laboratories, Chugai Pharmaceutical Co., Ltd., 1-135 Komakado, Gotemba, Shizuoka, 412-8513, Japan

Full list of author information is available at the end of the article
}

and reduces serum immunoglobulin via the inhibition of folic acid metabolism [4-6]. However, loss or reduction of its efficacy is a major problem in the treatment of RA. The efficacy of MTX varies among treated patients, and approximately $30 \%$ of patients discontinue administration within one year [7-9].

Transporters play important roles in drug disposition through their involvement in the pathways of drug absorption, distribution, and excretion, and would be among the major determinants of the pharmacological and/or toxicological effects of drugs. The ubiquitously expressed reduced folate carrier SLC19A1 is considered the major transport route for MTX $[10,11]$. As MTX 
cannot pass through the plasma membrane because of the anionic nature of MTX, SLC19A1-mediated cellular uptake should be regarded as the first step in the mode of action of MTX [12-14]. Previous studies using malignant cells showed that resistance to MTX is associated with reduced expression and activity of SLC19A1 $[15,16]$. However, the relationship between the efficacy of MTX and the expression of SLC19A1 in arthritic animals and RA patients is not fully understood.

Glucose 6-phosphate isomerase (GPI)-induced arthritis is widely studied, not only for the understanding of the pathogenesis of RA, but also for the development of new therapeutics, because its pathological features are similar to those of RA with pannus formation, cartilage or bone erosions, and angiogenesis in the synovium [17]. Moreover, it has been reported that cytotoxic $\mathrm{T}$-lymphocyte antigen 4 immunoglobulin fusion protein (CTLA-4Ig) and antibodies to tumor necrosis factor- $\alpha$ (TNF- $\alpha$ ) and IL-6, which are very effective in the treatment of RA patients [18-20], also show therapeutic effects in GPI-induced arthritis [21]. However, the efficacy of MTX has not yet been evaluated in this model.

In the present study we examined the relationship between the efficacy of MTX and the expression of SLC19A1 in GPI-induced arthritis. We found that IL-6 regulated the expression of SLC19A1, so we also studied the effect of concomitant use of MTX and anti-IL-6 receptor (IL-6R) antibody in this arthritis model.

\section{Materials and methods Animals}

Male DBA/1J mice were purchased from Charles River Japan (Yokohama, Japan). The mice were specific pathogen-free and were kept in cages in a room maintained at 20 to $26^{\circ} \mathrm{C}$ at a relative humidity of 35 to $75 \%$. The experimental protocol was approved by the Institutional Animal Care and Use Committee of Chugai Pharmaceutical Co., Ltd.

\section{Induction of glucose-6-phosphate isomerase-induced arthritis}

GPI-induced arthritis was induced as previously described, with modifications [21]. In brief, male DBA/ 1J mice ( 6 weeks old) were immunized intradermally at the base of the tail with $300 \mu \mathrm{g}$ of recombinant GPI-glutathione S-transferase fusion protein (GPI-GST) emulsified with an equal volume of complete adjuvant H37Ra (DIFCO, Detroit, MI, USA). Pertussis toxin (200 ng/200 $\mu \mathrm{L}$ ) was injected on the day of immunization and 2 days after immunization. Clinical symptoms of arthritis were evaluated visually and assigned a scale of 0 to 3 for each limb (maximum score/mouse $=12$ ).

\section{Treatment regimen}

MTX (Sigma Aldrich, St Louis, MO, USA) dissolved in 7\% sodium bicarbonate solution was given orally 3 times a week from the first day of immunization. Ten days after immunization, mice were intraperitoneally injected once with $4 \mathrm{mg}$ of rat anti-mouse IL-6R monoclonal antibody, MR16-1 [22]. The vehicle group mice were administered $7 \%$ sodium bicarbonate solution orally, and were intraperitoneally injected with phosphate buffer saline (PBS). The MTX group mice were administered MTX orally, and were intraperitoneally injected with PBS. The MR16-1 group mice were administered $7 \%$ sodium bicarbonate solution orally and were intraperitoneally injected with MR16-1. The MTX plus MR16-1 group mice were administered MTX orally and were intraperitoneally injected with MR16-1. Each group consisted of 8 or 9 animals.

\section{Analysis of gene expressions in mouse whole hind limbs} Immediately after the animals were killed, whole hind limbs were immersed in RNAlater RNA Stabilization Reagent (Qiagen, Valencia, CA, USA) and stored at $-80^{\circ}$ $C$ until total RNA extraction. The whole hind limbs were excised, immediately soaked in TRIzol (Invitrogen, Carlsbad, CA, USA), and crushed in a bead mill (TissueLyser II; Qiagen, Valencia, CA, USA). Total RNA was extracted using an RNeasy kit (Qiagen) according to the kit manufacturer's protocol. Amounts of total RNA obtained from a single whole hind limb were 4.5 to 18 $\mu \mathrm{g}$ (intact mice), 15to $60 \mu \mathrm{g}$ (non-treated immunized mice), 9 to $60 \mu \mathrm{g}$ (MTX-treated immunized mice), 12 to $30 \mu \mathrm{g}$ (MR16-1-treated immunized mice), and 4.2 and $30 \mu \mathrm{g}$ (MTX- and MR16-1-treated immunized mice). cDNA was synthesized with an Omniscript RT kit (Qiagen) using random 9-mer primers (TaKaRa, Shiga, Japan) according to the kit manufacturer's protocol. Quantitative real-time polymerase chain reaction (PCR) was performed by running a TaqMan gene expression assay (Applied Biosystems, Foster City, CA, USA), targeting mouse SLC19A1, IL-6, TNF- $\alpha$, and glyceraldehyde-3-phosphate dehydrogenase (GAPDH), on an ABI PRISM 7500 system (Applied Biosystems) according to the manufacturer's protocol.

\section{Analysis of gene expressions in mouse immune cells}

For CD4 T cell and B cell subset sorting, splenocytes were labeled with antibodies to CD4 and B220 and sorted to $97 \%$ purity by using a fluorescence-activated cell sorter (FACSAria III; BD Biosciences, Franklin Lakes, NJ, USA). Total RNA was extracted using an RNeasy kit (Qiagen) according to the kit manufacturer's protocol. Synthesis of cDNA and measurement of mRNA levels by quantitative real-time PCR were performed by the same methods as described above. 
Isolation and culture of mouse synovial cells

Arthritic mice were killed and the synovial tissues removed from their hind limbs. Synovial tissues were incubated at $37^{\circ} \mathrm{C}$ for $180 \mathrm{~min}$ in $\alpha$-MEM supplemented with $10 \%$ fetal bovine serum (FBS) and containing $0.5 \mathrm{mg} / \mathrm{mL}$ of Liberase Blendzyme2 (Roche Diagnostics, Basel, Switzerland). After incubation of the synovial tissues with the Liberase Blendzyme2, the resulting cells were cultured in a culture flask in $\alpha$-MEM supplemented with $10 \%$ FBS and the non-adherent cells were removed and discarded. Synovial cells were then subcultured in $\alpha$-MEM supplemented with $10 \%$ FBS to a density of $2 \times 10^{5}$ cells $/ 35 \mathrm{~mL}$ in a T175 flask. In this study, synovial cells from passages two to five were used.

\section{Analysis of gene expressions in synovial cells}

Synovial cells $\left(5 \times 10^{4}\right.$ cells $/ 2 \mathrm{~mL} /$ well $)$ were cultured in $\alpha$-MEM supplemented with $10 \%$ FBS for $24 \mathrm{~h}$. After this pre-culture, cells were cultured with mouse IL-6 (Peprotech, Rocky Hill, NJ, USA) and soluble mouse IL6R (R\&D Systems, Minneapolis, MN, USA), TNF- $\alpha$, or MTX for $24 \mathrm{~h}$. Total RNA was extracted using an RNeasy kit (Qiagen) according to the kit manufacturer's protocol. cDNA was synthesized with an Omniscript RT kit (Qiagen) using random 9-mer primers (Takara) according to the kit manufacturer's protocol. Quantitative real-time PCR was performed by running a TaqMan gene expression assay, targeting mouse SLC19A1, multidrug resistance protein-1 (MRP-1), breast cancer resistance protein (BCRP), and GAPDH, on an ABI PRISM 7500 system (Applied Biosystems) according to the manufacturer's protocol.

\section{Proliferation assay}

Synovial cells $\left(5 \times 10^{3}\right.$ cells $/ 0.2 \mathrm{~mL} /$ well $)$ were cultured either with medium alone or with mouse IL-6, mouse sIL$6 \mathrm{R}$, and MTX in a 96-well flat bottom plate for 3 days. Synovial cell proliferation was assessed using the Cell Proliferation ELISA system (GE Healthcare UK, Buckinghamshire, UK) according to the manufacturer's instructions. Briefly, bromodeoxyuridine (BrdU) was added for the last $3 \mathrm{~h}$, and its uptake was detected with anti-BrdU antibody. Substrate was added to elicit a colorimetric reaction, and absorbance at $450 \mathrm{~nm}$ was measured using a microplate reader (SLT Inc., Salzburg, Austria). The data are expressed in terms of optical density (OD) values.

\section{Measurement of the uptake of MTX}

Synovial cells $\left(5 \times 10^{4}\right.$ cells $/ 2 \mathrm{~mL} /$ well $)$ were cultured for $24 \mathrm{~h}$ in $\alpha$-MEM supplemented with $10 \%$ FBS. After this pre-culture, cells were cultured with mouse IL-6 and mouse sIL-6R for an additional $24 \mathrm{~h}$. After washing cells with PBS, cells were incubated in the presence $100 \mathrm{nM}$ of
Alexa Fluor 488 conjugated MTX (Invitrogen) for $5 \mathrm{~h}$. After incubation, cells were treated with trypsin-EDTA (Gibco, Grand Island, NY, USA) to obtain a single cell suspension. Intracellular accumulation of MTX was measured with a fluorescence-activated cell sorter (FACSCanto II; BD Biosciences) and calculated mean fluorescence intensities (MFIs) were analyzed using FACSDiva software (BD Bioscience).

\section{Measurement of cytokine levels in serum}

Serum samples were collected 15 days after immunization, and the concentrations of serum amyloid A (SAA) and IL- 6 were measured by SAA mouse ELISA kit (Invitrogen) and Mouse IL-6 Quantikine ELISA Kit (R\&D systems), respectively.

\section{Statistical analysis}

Statistical significances were estimated by Wilcoxon's test, unpaired $t$-test, and Dunnett's multiple comparison test using a statistical software package (SAS Institute Japan, Tokyo, Japan), with the significance level set to $5 \%$.

\section{Results}

\section{Efficacy of MTX, and SLC19A1 expression in GPI-induced} arthritis

MTX was administered orally 3 times a week for 4 weeks. MTX $(10 \mathrm{mg} / \mathrm{kg})$ suppressed the progression of arthritis, but from day 20 its efficacy gradually diminished (Figure 1A).

The mRNA expressions of SLC19A1 in whole hind limbs and immune cells were examined 15 days after immunization (peak of arthritis). The SLC19A1 expression in immunized mice was lower than that in intact mice (Figure 1B-D). Moreover, the expression level of SLC19A1 in whole hind limbs was further decreased by treatment with MTX (Figure 1B). TNF- $\alpha$ and IL-6 mRNA expressions in whole hind limbs were up-regulated in immunized mice with arthritis compared with intact mice, and MTX treatment did not reduce TNF- $\alpha$ or IL-6 mRNA expressions (Figure 1E, F). IL-1 mRNA expression was not detectable (data not shown).

\section{Effect of MTX and IL-6 on the expression of SLC19A1 in synovial cells}

We examined the effects of MTX, TNF- $\alpha$ and IL- 6 on the expression of SLC19A1 in synovial cells. IL-6 or sIL6R alone did not affect SLC19A1 mRNA expression (data not shown), but IL-6 + sIL-6R significantly decreased SLC19A1 expression in synovial cells (Figure 2A). MTX, but not TNF- $\alpha$, significantly decreased the expression of SLC19A1 in synovial cells (Figure 2B, C). Moreover, in the presence of IL- $6+$ sIL-6R, MTX further reduced SLC19A1 expression (Figure 2D). 


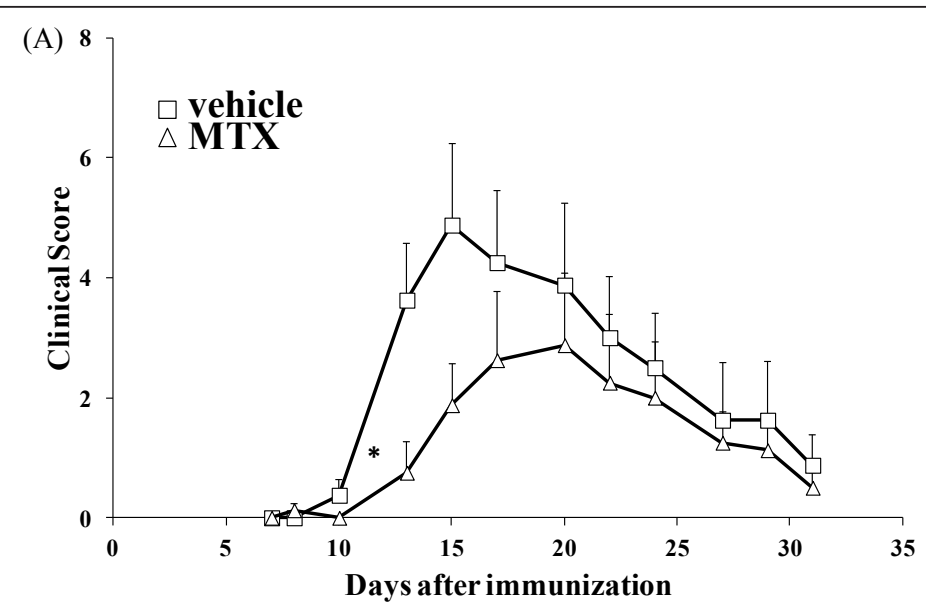

\begin{abstract}
(B) Whole hind limbs
\end{abstract}

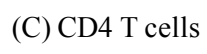

(D) B cells
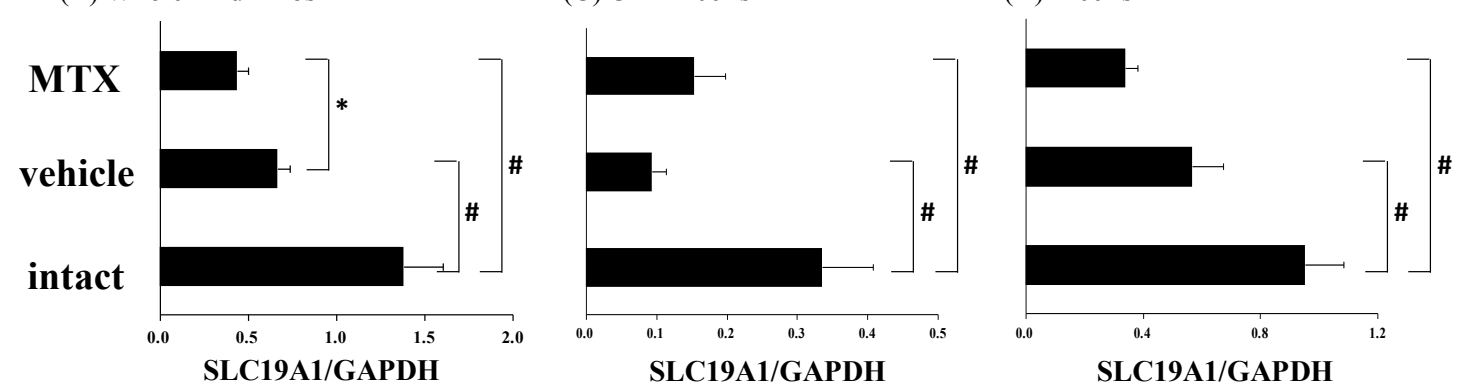

(E)

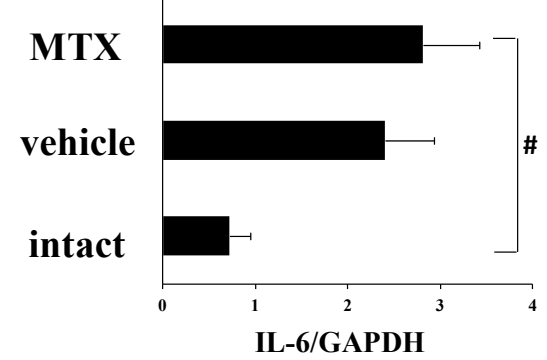

(F)

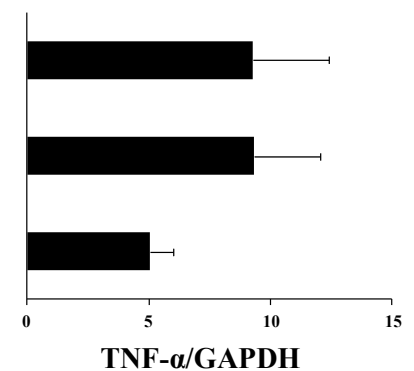

Figure 1 Effect of methotrexate (MTX) in the glucose 6-phosphate isomerase (GPI)-induced arthritis model. Mice were immunized with GPIGST emulsified in complete adjuvant. MTX (10 mg/kg) was administered 3 times a week from the first day of immunization. (A) Arthritis score was assessed as described in the Methods section. Each symbol indicates the mean and standard error (SE) of 8 animals. Statistically significant differences in clinical scores were analyzed by Wilcoxon's test $\left({ }^{*} P<0.05\right)$. SLC19A1 mRNA expressions in (B) whole hind limbs, (C) CD4 T cells, and (D) B cells were measured by real-time polymerase chain reaction (PCR). (E) IL-6 and (F) TNF- $\alpha$ mRNA expression in whole hind limbs was measured by real-time PCR. Samples were obtained on day 15. Each bar and error bar indicates the mean and SE of 8 animals. Statistical significance was analyzed by Dunnett's multiple comparison test $(\# P<0.05)$ or unpaired $t$-test $(* P<0.05)$. GAPDH, glyceraldehyde-3-phosphate dehydrogenase.

To investigate if MTX and IL-6 + sIL-6R affected the accumulation of MTX in synovial cells, the synovial cells were pre-treated with MTX and IL-6 + sIL-6R, and then MTX uptake into cells was examined. As shown in Figure 2E, pre-treatment with IL-6 + sIL-6R, or with MTX, reduced the accumulation of fluorescent conjugated MTX in synovial cells, and pre-treatment with IL$6+$ sIL-6R + MTX further reduced the accumulation of fluorescent conjugated MTX in synovial cells.
Effect of IL-6 on MTX-induced anti-proliferative effect Because we previously reported that MTX suppressed the proliferation of synovial cells from RA patients [23], we examined the effect of IL-6 + sIL-6R on MTX-induced suppression of proliferation of mouse synovial cells in vitro. MTX clearly inhibited the proliferation of mouse synovial cells in a dose-dependent manner (Figure 3). Interestingly, the inhibitory effect of MTX was weakened by the co-addition of IL-6 + sIL-6R. 

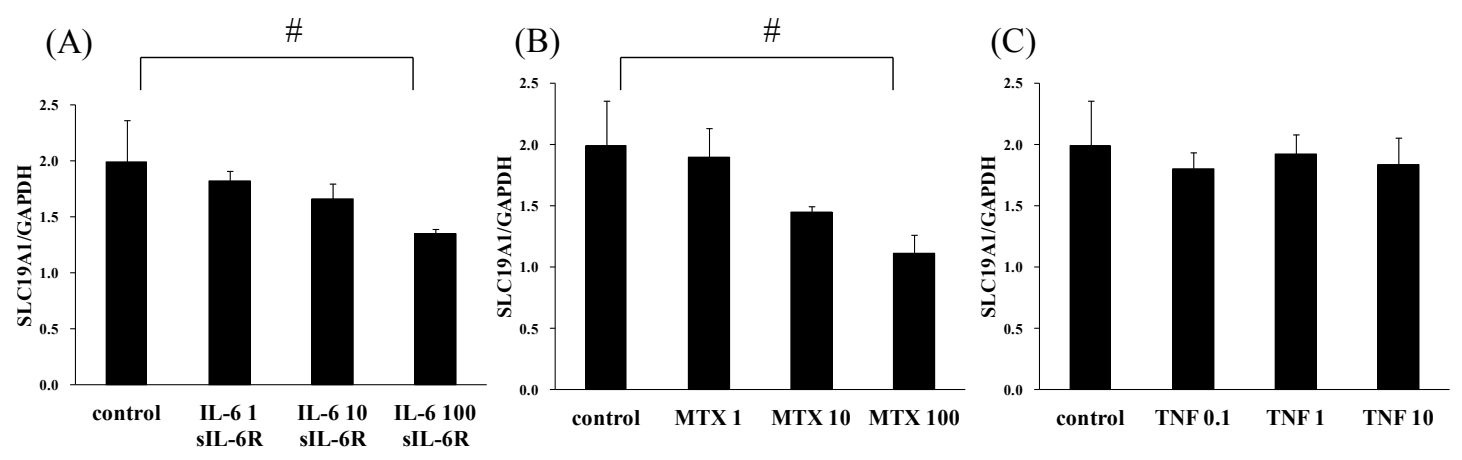

(D)

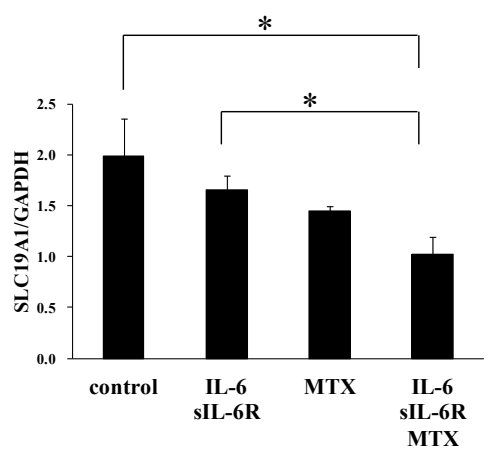

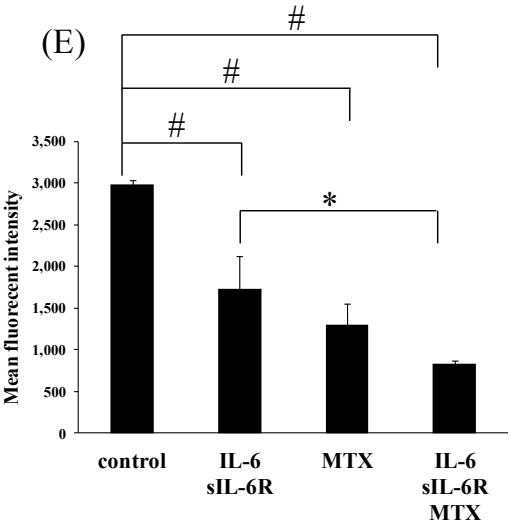

Figure 2 Interleukin-6 (IL-6) and methotrexate (MTX) reduced SLC19A1 expression and uptake of MTX into mouse synoviocytes Synoviocytes from arthritic mice were cultured for $24 \mathrm{~h}$ with $(\mathbf{A}) \mathrm{IL}-6(1,10,100 \mathrm{ng} / \mathrm{mL})+$ soluble IL-6 receptor (sIL-6R) $(100 \mathrm{ng} / \mathrm{mL}),(\mathbf{B}) \mathrm{MTX}(1,10$, $100 \mathrm{nM})$, (C) tumor necrosis factor $-\alpha$ (TNF- $\alpha)(0.1,1,10 \mathrm{ng} / \mathrm{mL})$, or (D) IL-6 (100 ng/mL) + slL-6R (100 ng/mL), MTX (100 nM), or IL-6 (100 ng/mL) + slL-6R (100 ng/mL) + MTX (100 nM). After culturing, cell lysate was collected and the mRNA expression for SLC19A1 was measured by real-time polymerase chain reaction. (E) Mouse synoviocytes were cultured for $24 \mathrm{~h}$ with IL-6 (100 ng/mL) + slL-6R (100 ng/mL), MTX (100 nM), or IL-6 $(100 \mathrm{ng} / \mathrm{mL})+s \mathrm{IL}-6 R(100 \mathrm{ng} / \mathrm{mL})+$ MTX (100 nM). The uptake of Alexa Fluor 488 conjugated MTX (100 nM) was quantified by measuring the fluorescence emission for each sample. Results are expressed in arbitrary units of fluorescence intensity. Each column and vertical line represents the mean and standard deviation of triplicate cultures. Statistical significance was analyzed by Dunnett's multiple comparison test (\#P<0.05) or unpaired $t$-test $(* P<0.05)$.

\section{Concomitant use of MTX and anti-IL-6R antibody in GPI- induced arthritis}

Iwanami et al. reported that the development of GPIinduced arthritis was almost completely blocked by the injection of MR16-1 on days 0, 3, or 8 after immunization, whereas injection of MR16-1 on day 14, at the peak of arthritis, did not ameliorate arthritis, because injection of MR16-1 on day 14 did not inhibit $\mathrm{T}_{\mathrm{h}} 17$ induction [17]. A similar result was obtained in our study; namely, injection of MR16-1 on days 0 or 5 completely blocked the onset of arthritis, but the injection on day 10 did not ameliorate arthritis (data not shown). From these results, we decided to administer MR16-1 on day 10, because this regimen can exclude the direct effect of MR16-1 on the progression of arthritis.

Next, we examined whether the combination use of MTX and MR16-1 would affect the inhibitory effect of MTX on GPI-induced arthritis. Surprisingly, although MR16-1 monotherapy did not reduce arthritis score, concomitant use of MTX and MR16-1 significantly reduced the progression of arthritis compared with the vehicle group or the MTX group (Figure 4A).

To examine whether this phenomenon was induced by blocking IL-6, we measured concentrations of IL-6 and SAA in serum on day 15. Serum concentration of IL-6 was significantly elevated in vehicle-treated arthritic mice compared with intact mice (Figure 4B). Although serum IL-6 concentration did not significantly change in the MTX group compared with the vehicle-treated group, dramatic elevation of serum IL-6 level was observed in the MR16-1 group and the MTX plus MR16-1 group. It has been shown that IL-6 induces SAA [24], and because SAA is a beneficial marker of IL- 6 activity, we also measured the serum level of SAA. Levels of SAA in the vehicle group were increased to 100 times the levels in intact mice, and were only slightly reduced in MTX-treated immunized mice. On the other hand, SAA induction was completely inhibited in the MR16-1 group and the MTX 


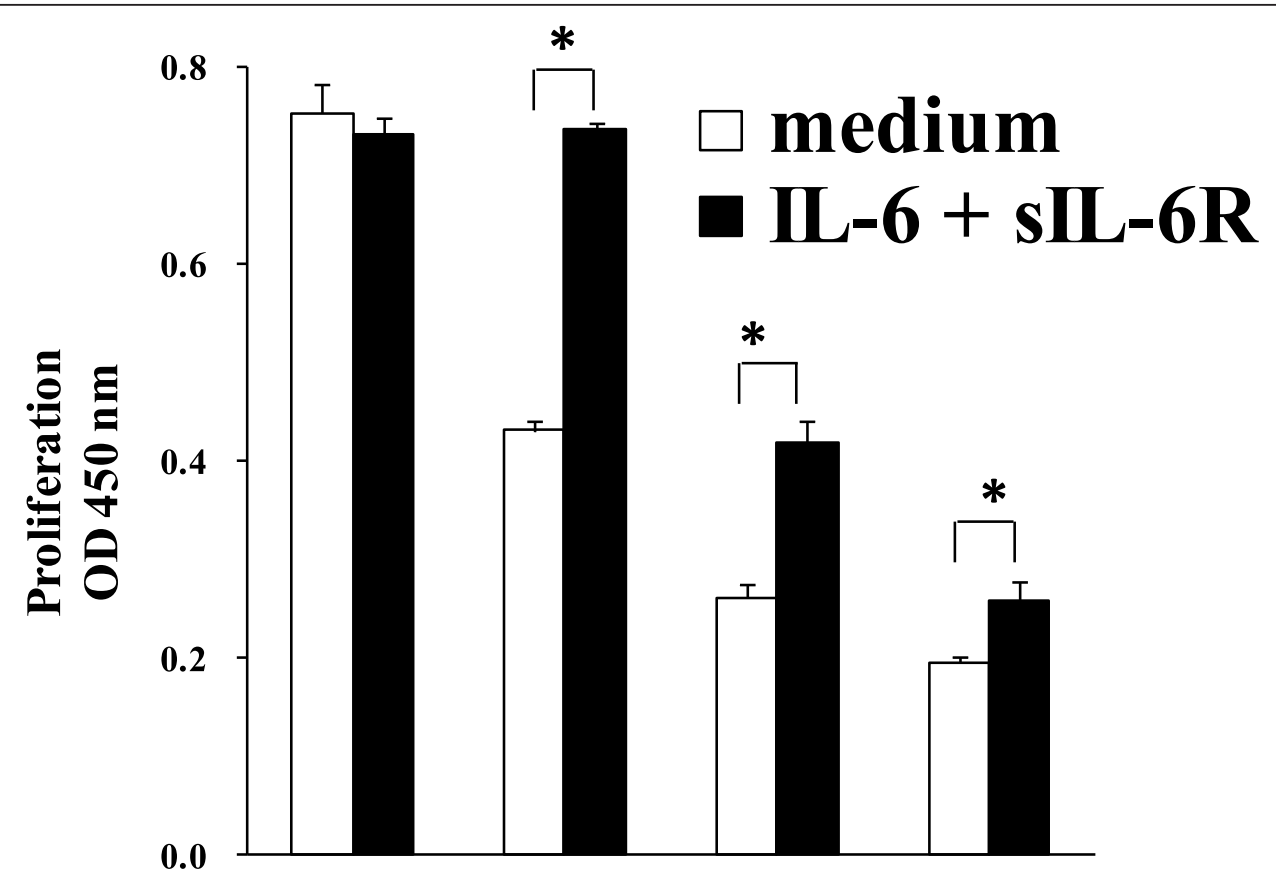

MTX

nM

$\begin{array}{llll}0 & 10 & 100 & 1,000\end{array}$

Figure 3 Effect of interleukin-6 (IL-6) on methotrexate (MTX)-induced anti-proliferative effect. Synoviocytes from arthritic mice were cultured for $24 \mathrm{~h}$ with methotrexate $(0,10,100,1,000 \mathrm{nM})$ with medium alone or in the presence of $\mathrm{IL}-6(100 \mathrm{ng} / \mathrm{mL})+$ soluble IL-6 receptor (sIL-6R) $(100 \mathrm{ng} / \mathrm{mL})$. After culturing, cell proliferation was measured by uptake of bromodeoxyuridine. Statistical significance was analyzed by the unpaired $t$-test $\left({ }^{*} P<0.05\right)$. Each column and vertical line indicates the mean and standard deviation of quadruplicate cultures.

plus MR16-1 group (Figure 4C). We also noted that the body weights in all groups were unchanged throughout the experiments (data not shown).

The expressions of SLC19A1 mRNA in whole hind limbs, CD4 T cells and B cells were increased in the MR16-1 group and in the MTX plus MR16-1 group compared with those in the vehicle group (Figure 5A-C). Moreover, the levels of SLC19A1 mRNA expression significantly increased in the MTX plus MR16-1 group compared with those in the MTX group.

\section{Discussion}

Several transporters are associated with MTX uptake into cells, and these are expected to be important in determining the response and resistance to MTX $[15,16]$. SLC19A1 is one of the most important transporters by which MTX is taken up by cells; its expression level therefore, can predict response to MTX therapy in cancer patients $[15,16]$. In this study, we examined the relationship between the efficacy of MTX and the expression of SLC19A1 in an arthritic animal model. We found that: 1) the expression of SLC19A1 was significantly reduced in inflamed whole hind limbs; 2) MTX itself and IL-6 + sIL-6R, but not
TNF- $\alpha$, directly decreased the expression of SLC19A1 in synovial cells; 3) MTX and IL-6 + sIL-6R reduced the uptake of MTX into synovial cells and 4) the efficacy of MTX on the arthritis score was augmented by concomitant use of anti-IL-6R antibody. These results strongly suggest that the expression level of SLC19A1 is correlated with the efficacy of MTX in arthritic animals.

MTX is very effective in the therapy of patients with RA. However, the loss or reduction of its efficacy is a major problem. Although its precise mechanism is not fully understood, some reports have mentioned that specific cell membrane-associated drug efflux transporters, such as multidrug resistance protein-1 (MRP-1) and breast cancer resistance protein (BCRP), are induced upon therapy with MTX $[25,26]$. In the present study, we found that MTX reduced the expression of SLC19A1 in the whole hind limbs of arthritic mice. This mechanism may also be involved in secondary refractoriness to MTX in RA patients.

We also found that intracellular concentration of MTX was significantly lower in IL-6 + sIL-6R-treated synovial cells than in IL-6-nontreated cells and that the anti-proliferative effect of MTX was inhibited in the 


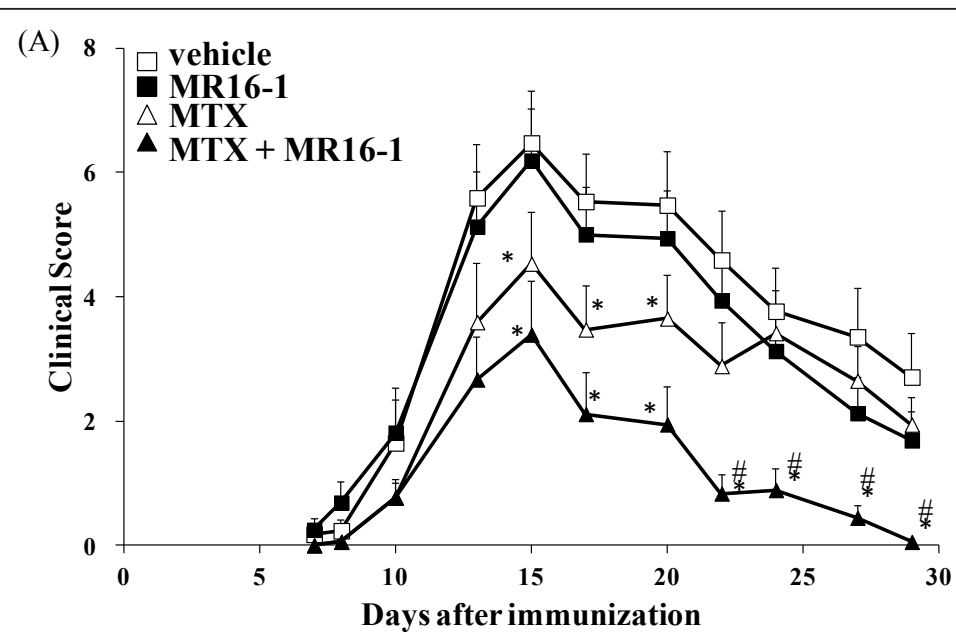

(B)

(C)

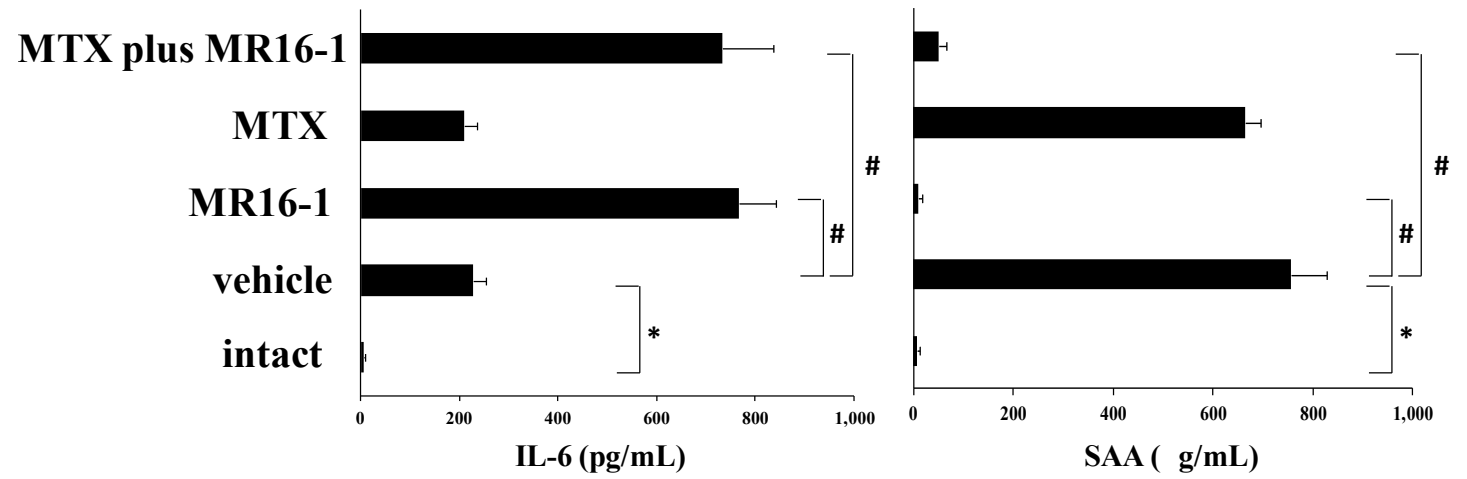

Figure 4 Effect of concomitant use of methotrexate (MTX) and anti-interleukin-6 receptor (IL-6R) antibody on arthritis score. MTX (10 $\mathrm{mg} / \mathrm{kg}$ ) was administered 3 times a week from the first day of immunization. Rat anti-mouse IL-6R monoclonal antibody (MR16-1) (4 mg/mouse) was injected on day 10. (A) Arthritis score was assessed as described in the Methods section. Each symbol indicates the mean and standard error (SE) of 8 to 9 animals. Statistical significance was analyzed by Wilcoxon's test $\left(P<0.05\right.$, ${ }^{*} v$ s. vehicle; \#vs. MTX). Levels of (B) IL-6 and (C) serum amyloid A (SAA) were measured by ELISA. Sera were obtained on day 15. Each bar and error bar indicates the mean and SE of 8 to 9 animals. Statistical significance was analyzed by Dunnett's multiple comparison test $(\# P<0.05)$ or the unpaired $t$-test $\left.{ }^{*} P<0.05\right)$.

(A) Whole hind limbs

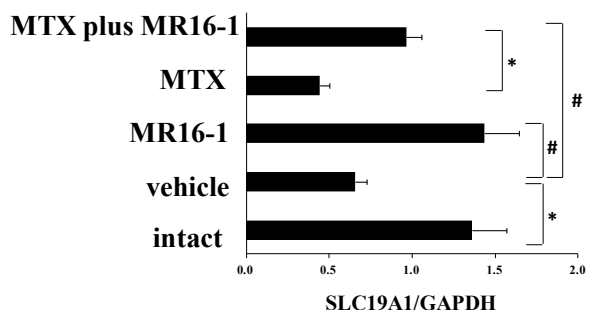

(B) CD4 T cells

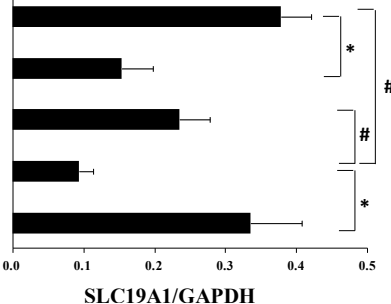

(C) B cells

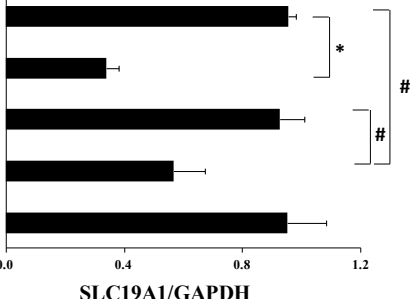

Figure 5 Effect of concomitant use of methotrexate (MTX) and anti-interleukin-6 receptor (IL-6R) antibody on SLC19A1 expression. MTX (10 mg/kg) was administered 3 times a week from the first day of immunization. Rat anti-mouse IL-6R monoclonal antibody (4 mg/mouse) was injected on day 10. SLC19A1 mRNA expression in (A) whole hind limbs, (B) CD4 T cells, and (C) B cells were measured by real-time polymerase chain reaction. Each bar and error bar indicates the mean and standard error of 8 to 9 animals. Statistical significance was analyzed by the unpaired $t$-test $\left({ }^{*} P<0.05\right)$ or Dunnett's multiple comparison test $(\# P<0.05)$. GAPDH, glyceraldehyde-3-phosphate dehydrogenase. 
presence of IL-6 + sIL-6R. MTX enters the cells mainly via SLC19A1 and effluxes from cells via ATP-binding cassette $(A B C)$ transporters $[25,26]$. As shown in Figure 2, IL-6 + sIL-6R inhibited the expression of SLC19A1. Moreover, it is reported that MTX-resistant malignant cells highly express $\mathrm{ABC}$ transporters such as MRP-1 and BCRP $[25,26]$. We examined the effect of IL-6 + sIL-6R on these two ABC transporters, but IL-6 + sIL-6R did not affect their expression (see Additional file 1). This result suggests that the decrease in intracellular concentration of MTX by IL- 6 + sIL-6R results from the inhibition of MTX uptake via reduction of the influx transporter, and not by accelerated excretion of MTX from cells. MTX undergoes intracellular polyglutamation by folylpolyglutamate synthetase [27]. MTX-polyglutamates are kept within cells for longer periods than MTX itself [28]. In addition, polyglutamation increases the affinity of MTX for its target enzymes such as dihydrofolate reductase, thymidylate synthase, and 5-aminoimidazole-4-carboxamide ribonucleotide transformylase [29]. MTX-polyglutamates are converted to MTX by $\gamma$-glutamylhydrolase [30] and effluxed from cells by ABC transporters. We examined the effect of IL- 6 + sIL-6R on these enzymes, but found that IL- $6+$ sIL-6R did not affect induction of these enzymes (data not shown).

We demonstrated that the whole hind limbs of arthritic mice showed lower SLC19A1 expression than whole hind limbs of normal mice, which was reversed by IL- 6 blockade, and that MTX treatment reduced SLC19A1 expression in arthritic mice. We also obtained similar results in an in vitro study using synovial cells from arthritic mice; namely, IL-6 + sIL-6R and MTX each reduced SLC19A1 expression in synovial cells, and the combination of IL-6 + sIL-6R + MTX further reduced its expression. Although a precise mechanism for the reduction of SLC19A1 expression by MTX and IL-6 + sIL-6R is still unknown, our results strongly suggest that IL-6 + sIL-6R and MTX each suppressed SLC19A1 expression by an independent mechanism. We are currently planning a study to verify how IL- 6 + sIL6R and MTX suppress SLC19A1 expression.

IL-6 exerts its biological activities through two membrane molecules, a ligand-binding $80 \mathrm{kDa}$ chain (IL-6R) and a non-ligand-binding signal transducer gp130 [31]. After binding of IL- 6 to membrane-bound IL-6R (mIL6R), the IL-6/IL-6R complex associates with gp130, and a signal is transmitted into the cell. In addition, sIL-6R, which lacks trans-membrane and cytoplasmic domains, can also associate with gp130 in the presence of IL- 6 and transduce the signal via gp130. Therefore, both mIL-6R and sIL-6R play essential roles in IL-6 signaling. In this study, IL-6 + sIL-6R, but not IL-6 or sIL-6R alone, could decrease SLC19A1 in synovial cells, suggesting that synovial cells express gp130 but not mIL-6R. As there is sufficient sIL-6R in synovial fluid and blood, we think that the phenomenon seen in vitro in this study is likely to occur in vivo.

In RA patients as well as in arthritic animals, IL-6 concentration in serum and synovial fluid is higher than in healthy individuals or patients with osteoarthritis [32]. Therefore, IL-6-induced reduction of SLC19A1 expression is very likely to occur in patients with RA. More recently, Takeuchi et al. reported that combination therapy of anti-IL-6 therapy with tocilizumab and MTX showed a more remarkable effect as assessed by the Health Assessment Questionnaire-Disability Index (HAQ-DI) and by the 28-joint disease activity score (DAS28) than tocilizumab monotherapy in daily clinical practice [33]. This result could be partly explained by enhanced MTX efficacy resulting from reversal of the decrease in SLC19A1 expression by tocilizumab. Further studies of the relationship between expression of SLC19A1 and clinical response after MTX and anti-IL-6 therapy in patients with RA are needed to confirm our hypothesis.

Serum IL-6 concentration was dramatically up-regulated in the MR16-1-treated groups. We previously showed that the elevation of IL- 6 levels in serum following treatment with anti-IL-6R antibodies is due to the inhibition of IL-6R-mediated clearance of IL-6 from the blood, and is not the result of induction of IL-6 protein synthesis to compensate for the IL- 6 blockade or release of free IL-6 from complexes [34]. Moreover, MR16-1 treatment completely inhibited the induction of SAA. These data clearly demonstrate that IL- 6 signaling was completely inhibited by MR16-1 in this study.

TNF- $\alpha$ antagonists in combination with MTX are highly effective treatments for severe RA [35]. When anti-TNF- $\alpha$ antibodies are used in monotherapy, antibodies against the anti-TNF- $\alpha$ antibodies are often induced. Since antibodies to the anti-TNF- $\alpha$ antibodies decrease serum levels of the anti-TNF- $\alpha$ antibody and diminish the therapeutic effects [36-39], MTX combination is mandatory in treatments with infliximab, adalimumab, or golimumab. Of interest, TNF- $\alpha$-receptor-Fcfusion protein (etanercept) has been shown to be effective for RA even as a monotherapy because antibodies against etanercept are rarely produced [40]. However, a recent report has shown that, in MTX-refractory patients with RA, clinical response is better with etanercept plus MTX than with etanercept alone [41]. Although we showed that TNF- $\alpha$ did not change the expression of SLC19A1, because TNF- $\alpha$ blockade significantly reduces serum levels of IL-6 in RA patients [42], TNF- $\alpha$ blockade may augment the efficacy of MTX in a manner similar to that of IL-6 blockade. 


\section{Conclusion}

In the present study, we demonstrated for the first time that the expression of the reduced folate transporter SLC19A1, which is important for MTX uptake into cells, is strongly related to the efficacy of MTX in an arthritis model. We also showed that IL- 6 reduced the efficacy of MTX via the inhibition of SLC19A1 expression; therefore, IL-6 inhibition may improve responsiveness to MTX in patients with RA who show inadequate response to MTX.

\section{Additional material}

Additional file 1: A figure showing mRNA expression for multidrug resistance protein (MRP-1) and breast cancer resistance protein (BCRP). Synoviocytes from arthritic mice were cultured for $24 \mathrm{~h}$ with interleukin-6 (IL-6) (1, 10, $100 \mathrm{ng} / \mathrm{mL})+$ soluble IL-6 receptor (sIL-6R) (100 $\mathrm{ng} / \mathrm{mL}$ ) or methotrexate $(1,10,100 \mathrm{nM})$. After culturing, cell lysate was collected and mRNA expression for (A) MRP-1 and (B) BCRP was measured by real-time polymerase chain reaction. Each column and vertical line represents the mean and standard deviation of triplicate cultures. Statistical significance was analyzed by Dunnett's multiple comparison test or the unpaired $t$-test. GAPDH, glyceraldehyde-3phosphate dehydrogenase.

\section{Author details}

${ }^{1}$ Product Research Department, Fuji-Gotemba Research Laboratories, Chugai Pharmaceutical Co., Ltd., 1-135 Komakado, Gotemba, Shizuoka, 412-8513, Japan. ${ }^{2}$ Division of Clinical Immunology, Doctoral Program in Clinical Science, Graduate School of Comprehensive Human Sciences, University of Tsukuba, 1-1-1 Tennodai, Tsukuba, Ibaraki, 305-8575, Japan.

\section{Authors' contributions}

$\mathrm{MH}$ was responsible for the acquisition of data, data analysis, interpretation of data and drafting the manuscript; $H Y, K T$, and MS for the acquisition of data; IM and TS for drafting the manuscript and MM for the interpretation of data and drafting the manuscript. All authors read and approved the final manuscript.

\section{Competing interests}

$\mathrm{MH}, \mathrm{HY}, \mathrm{KT}, \mathrm{MS}$, and MM were, or currently are, employed by Chugai Pharmaceutical., Co., Ltd.

\section{Received: 24 November 2011 Revised: 9 April 2012}

Accepted: 30 April 2012 Published: 30 April 2012

\section{References}

1. Aletaha D, Smolen JS: DMARD use in early rheumatoid arthritis. Lessons from observations in patients with established disease. Clin Exp Rheumatol 2003, 21(5 Suppl 31):S169-S173.

2. Aletaha D, Stamm T, Kapral T, Eberl G, Grisar J, Machold KP, Smolen JS: Survival and effectiveness of leflunomide compared with methotrexate and sulfasalazine in rheumatoid arthritis: a matched observational study. Ann Rheum Dis 2003, 62:944-951.

3. Andersen PA, West SG, O'Dell JR, Via CS, Claypool RG, Kotzin BL: Weekly pulse methotrexate in rheumatoid arthritis. Clinical and immunologic effects in a randomized, double-blind study. Ann Intern Med 1985, 103:489-496

4. van Ede $A E$, Laan RF, Blom HJ, De Abreu RA, van de Putte LB: Methotrexate in rheumatoid arthritis: an update with focus on mechanisms involved in toxicity. Semin Arthritis Rheum 1998, 27:277-292.

5. Cronstein BN: The mechanism of action of methotrexate. Rheum Dis Clin North Am 1997, 23:739-755
6. Swierkot J, Szechiński J: Methotrexate in rheumatoid arthritis. Pharmacol Rep 2006, 58:473-492

7. Alarcón GS, Tracy IC, Blackburn WD Jr: Methotrexate in rheumatoid arthritis. Toxic effects as the major factor in limiting long-term treatment. Arthritis Rheum 1989, 32:671-676.

8. Aletaha D, Smolen JS: The rheumatoid arthritis patient in the clinic: comparing more than 1,300 consecutive DMARD courses. Rheumatology (Oxford) 2002, 41:1367-1374.

9. Maetzel A, Wong A, Strand V, Tugwell P, Wells G, Bombardier C: Metaanalysis of treatment termination rates among rheumatoid arthritis patients receiving disease-modifying anti-rheumatic drugs. Rheumatology (Oxford) 2000, 39:975-981.

10. Goldman ID, Lichtenstein NS, Oliverio VT: Carrier-mediated transport of the folic acid analogue, methotrexate, in the L1210 leukemia cell. J Biol Chem 1968, 243:5007-5017

11. Matherly LH, Goldman DI: Membrane transport of folates. Vitam Horm 2003, 66:403-456.

12. Cronstein BN: Molecular therapeutics. Methotrexate and its mechanism of action. Arthritis Rheum 1996, 39:1951-1960.

13. Cutolo M, Sulli A, Pizzorni C, Seriolo B, Straub RH: Anti-inflammatory mechanisms of methotrexate in rheumatoid arthritis. Ann Rheum Dis 2001, 60:729-735.

14. Ranganathan P, Eisen S, Yokoyama WM, McLeod HL: Will pharmacogenetics allow better prediction of methotrexate toxicity and efficacy in patients with rheumatoid arthritis? Ann Rheum Dis 2003, 62:4-9.

15. Gorlick R, Cole P, Banerjee D, Longo G, Li WW, Hochhauser D, Bertino JR: Mechanisms of methotrexate resistance in acute leukemia. Decreased transport and polyglutamylation. Adv Exp Med Biol 1999, 457:543-550.

16. Wong SC, Zhang L, Witt TL, Proefke SA, Bhushan A, Matherly LH: Impaired membrane transport in methotrexate-resistant CCRF-CEM cells involves early translation termination and increased turnover of a mutant reduced folate carrier. J Biol Chem 1999, 274:10388-10394.

17. Iwanami K, Matsumoto I, Tanaka-Watanabe $Y$, Inoue A, Mihara M, Ohsugi Y, Mamura M, Goto D, Ito S, Tsutsumi A, Kishimoto T, Sumida T: Crucial role of the interleukin-6/interleukin-17 cytokine axis in the induction of arthritis by glucose-6-phosphate isomerase. Arthritis Rheum 2008, 58:754-763.

18. Taylor PC, Williams RO, Maini RN: Anti-TNF alpha therapy in rheumatoid arthritis-current and future directions. Curr Dir Autoimmun 2000, 2:83-102.

19. Smolen JS, Beaulieu A, Rubbert-Roth A, Ramos-Remus C, Rovensky J, Alecock E, Woodworth T, Alten R, OPTION Investigators: Effect of interleukin-6 receptor inhibition with tocilizumab in patients with rheumatoid arthritis (OPTION study): a double-blind, placebo-controlled, randomised trial. Lancet 2008, 371:987-997.

20. Schiff M, Pritchard C, Huffstutter JE, Rodriguez-Valverde V, Durez P, Zhou X, Li T, Bahrt K, Kelly S, Le Bars M, Genovese MC: The 6-month safety and efficacy of abatacept in patients with rheumatoid arthritis who underwent a washout after anti-tumour necrosis factor therapy or were directly switched to abatacept: the ARRIVE trial. Ann Rheum Dis 2009, 68:1708-1714.

21. Matsumoto I, Zhang $H$, Yasukochi $T$, Iwanami $K$, Tanaka $Y$, Inoue A, Goto D, Ito S, Tsutsumi A, Sumida T: Therapeutic effects of antibodies to tumor necrosis factor-alpha, interleukin- 6 and cytotoxic T-lymphocyte antigen 4 immunoglobulin in mice with glucose-6-phosphate isomerase induced arthritis. Arthritis Res Ther 2008, 10:R66.

22. Okazaki M, Yamada Y, Nishimoto N, Yoshizaki K, Mihara M: Characterization of anti-mouse interleukin-6 receptor antibody. Immunol Lett 2002, 84:231-240.

23. Mihara M, Urakawa K, Takagi N, Moriya $Y$, Takeda $Y$ : In vitro and in vivo biological activities of a novel nonpolyglutamable anti-folate, MX-68. Immunopharmacology 1996, 35:41-46.

24. Hagihara K, Nishikawa T, Isobe T, Song J, Sugamata Y, Yoshizaki K: IL-6 plays a critical role in the synergistic induction of human serum amyloid A (SAA) gene when stimulated with proinflammatory cytokines as analyzed with an SAA isoform real-time quantitative RT-PCR assay system. Biochem Biophys Res Commun 2004, 314:363-369.

25. van der Heijden JW, Oerlemans R, Tak PP, Assaraf YG, Kraan MC, Scheffer GL, van der Laken CJ, Lems WF, Scheper RJ, Dijkmans BA, Jansen G: Involvement of breast cancer resistance protein expression on 
rheumatoid arthritis synovial tissue macrophages in resistance to methotrexate and leflunomide. Arthritis Rheum 2009, 60:669-677.

26. Agarwal V, Mittal SK, Misra R: Expression of multidrug resistance-1 protein correlates with disease activity rather than the refractoriness to methotrexate therapy in rheumatoid arthritis. Clin Rheumatol 2009, 28:427-433.

27. Baugh CM, Krumdieck CL, Nair MG: Polygammaglutamyl metabolites of methotrexate. Biochem Biophys Res Commun 1973, 52:27-34.

28. Chabner BA, Allegra CJ, Curt GA, Clendeninn NJ, Baram J, Koizumi S, Drake JC, Jolivet J: Polyglutamation of methotrexate. Is methotrexate a prodrug? J Clin Invest 1985, 76:907-912.

29. Kumar P, Kisliuk RL, Gaumont Y, Freisheim JH, Nair MG: Inhibition of human dihydrofolate reductase by antifolyl polyglutamates. Biochem Pharmacol 1989, 38:541-543.

30. Rhee MS, Wang Y, Nair MG, Galivan J: Acquisition of resistance to antifolates caused by enhanced gamma-glutamyl hydrolase activity. Cancer Res 1993, 53(10 Suppl):2227-2230.

31. Hibi M, Murakami M, Saito M, Hirano T, Taga T, Kishimoto T: Molecular cloning and expression of an IL-6 signal transducer, gp130. Cell 1990, 63:1149-1157.

32. Kotake S, Sato K, Kim KJ, Takahashi N, Udagawa N, Nakamura I, Yamaguchi A, Kishimoto T, Suda T, Kashiwazaki S: Interleukin-6 and soluble interleukin-6 receptors in the synovial fluids from rheumatoid arthritis patients are responsible for osteoclast-like cell formation. J Bone Miner Res 1996, 11:88-95.

33. Takeuchi T, Tanaka Y, Amano K, Hoshi D, Nawata M, Nagasawa H, Sato E, Saito K, Kaneko Y, Fukuyo S, Kurasawa T, Hanami K, Kameda H, Yamanaka H: Clinical, radiographic and functional effectiveness of tocilizumab for rheumatoid arthritis patients-REACTION 52-week study. Rheumatology (Oxford) 2011, 50:1908-1915.

34. Uchiyama Y, Yoshida H, Koike N, Hayakawa N, Sugita A, Nishimura T, Mihara M: Anti-IL-6 receptor antibody increases blood IL-6 level via the blockade of IL-6 clearance, but not via the induction of IL- 6 production. Int Immunopharmacol 2008, 8:1595-1601.

35. Salliot C, Finckh A, Katchamart W, Lu Y, Sun Y, Bombardier C, Keystone E: Indirect comparisons of the efficacy of biological antirheumatic agents in rheumatoid arthritis in patients with an inadequate response to conventional disease-modifying antirheumatic drugs or to an antitumour necrosis factor agent: a meta-analysis. Ann Rheum Dis 2011, 70:266-271.

36. Bendtzen K, Geborek P, Svenson M, Larsson L, Kapetanovic MC, Saxne T: Individualized monitoring of drug bioavailability and immunogenicity in rheumatoid arthritis patients treated with the tumor necrosis factor alpha inhibitor infliximab. Arthritis Rheum 2006, 54:3782-3789.

37. Radstake TR, Svenson M, Eijsbouts AM, van den Hoogen FH, Enevold C, van Riel PL, Bendtzen K: Formation of antibodies against infliximab and adalimumab strongly correlates with functional drug levels and clinical responses in rheumatoid arthritis. Ann Rheum Dis 2009, 68:1739-1745.

38. Wolbink GJ, Vis M, Lems W, Voskuyl AE, de Groot E, Nurmohamed MT, Stapel S, Tak PP, Aarden L, Dijkmans B: Development of antiinfliximab antibodies and relationship to clinical response in patients with rheumatoid arthritis. Arthritis Rheum 2006, 54:711-715.

39. Bartelds GM, Wijbrandts CA, Nurmohamed MT, Stapel S, Lems WF, Aarden L, Dijkmans BA, Tak PP, Wolbink GJ: Clinical response to adalimumab: relationship to anti-adalimumab antibodies and serum adalimumab concentrations in rheumatoid arthritis. Ann Rheum Dis 2007 66:921-926.

40. van Riel PL, Taggart AJ, Sany J, Gaubitz M, Nab HW, Pedersen R, Freundlich B, MacPeek D, Add Enbrel or Replace Methotrexate Study Investigators: Efficacy and safety of combination etanercept and methotrexate versus etanercept alone in patients with rheumatoid arthritis with an inadequate response to methotrexate: the ADORE study. Ann Rheum Dis 2006, 65:1478-1483,

41. Kameda H, Kanbe K, Sato E, Ueki Y, Saito K, Nagaoka S, Hidaka T, Atsumi T, Tsukano M, Kasama T, Shiozawa S, Tanaka Y, Yamanaka H, Takeuchi T: Continuation of methotrexate resulted in better clinical and radiographic outcomes than discontinuation upon starting etanercept in patients with rheumatoid arthritis: 52-week results from the JESMR Study. J Rheumatol 2011, 38:1585-1592.

42. Popa C, Netea MG, Radstake T, Van der Meer JW, Stalenhoef AF, van Riel PL, Barerra P: Influence of anti-tumour necrosis factor therapy on cardiovascular risk factors in patients with active rheumatoid arthritis. Ann Rheum Dis 2005, 64:303-305.

doi:10.1186/ar3821

Cite this article as: Hashizume et al: Interleukin-6 regulates anti-arthritic effect of methotrexate via reduction of SLC19A1 expression in a mouse arthritis model. Arthritis Research \& Therapy 2012 14:R96.

\section{Submit your next manuscript to BioMed Central and take full advantage of:}

- Convenient online submission

- Thorough peer review

- No space constraints or color figure charges

- Immediate publication on acceptance

- Inclusion in PubMed, CAS, Scopus and Google Scholar

- Research which is freely available for redistribution

Submit your manuscript at www.biomedcentral.com/submit
Biomed Central 